\title{
ANATOMICAL OBSERVATIONS ON THE COURSE OF THE AZYGOS VEIN (VENA AZYGOS MAJOR)
}

\author{
BY \\ HILEL NATHAN* \\ From the Department of Anatomy, the Hebrew University-Hadassah Medical School, Jerusalem, Israel
}

(RECEIVED FOR PUBLICATION MARCH 1,1960 )

In man, the azygos vein is described as ascending on the right side of the vertebral column until it curves anteriorly over the right bronchus to end in the superior vena cava. However, it has been observed that frequently the azygos vein is found to run part of its course on the left side of the midline. No description of this course has been found in current anatomical textbooks or other literature dealing with the subject (Morison, 1879; Butler and Balankura, 1952; Dal Zotto and Borsetto, 1954; Borsetto, 1956; Abrams, 1957). Azygos veins running on the left side have been observed in association with various malformations of the venous system, particularly a persistent left superior vena cava (Howden, 1886; McCotter, 1916; Smith, 1916; Huffmire and Bower, 1919; Keyes and Keyes, 1925; Butler and Balankura, 1952; Nguyen-Huu, 1957; Vakaet, Poppelier, and Vermeire, 1958).

The present work is a study of variations in the course of the azygos vein in relation to the midline; it is considered that it may be of assistance in the interpretation of radiographs of the azygos and other veins (Ottonello, 1931 ; Burke and Goldberg, 1949; Stauffer, LaBree, and Adams, 1951; Fischgold, Adam, Écoiffier, and Piéquet, 1952; Fleischner and Udis, 1952; Ellis and Bruwer, 1954; Süsse and Aurig, 1954; Tori, 1954; Lucarelli, Carnevali, and Vincre, 1955; Shuford and Weens, 1958; Schwartz, Handel, and Candel, 1959) as well as in the surgery of the region.

\section{MATERIAL}

One hundred and fifty dissecting-room cadavers $\dagger$ were the material for the present work. Of these, 130 were of adults, the great majority being of old people, and 20 were of stillborn infants.

\footnotetext{
* Formerly Hilel Notkovich.

+ From the Department of Anatomy of the Pennsylvania University, Philadelphia the Daniel Baugh Institute of Anatomy of the Jefferson Medical College, Philadelphia, and from our own Department of Anatomy.
}

\section{ObSERVATIONS AND DESCRIPTION}

In 69 cases $(53 \%)$ of the adult bodies, and in three cases $(15 \%)$ of the stillborn infants, the azygos vein, after beginning, as usually described, on the right side of the vertebral column, ran upwa:ds and to the left to cross the midline (Figs. 1 and 2); having ascended a variable distance on the left side of the

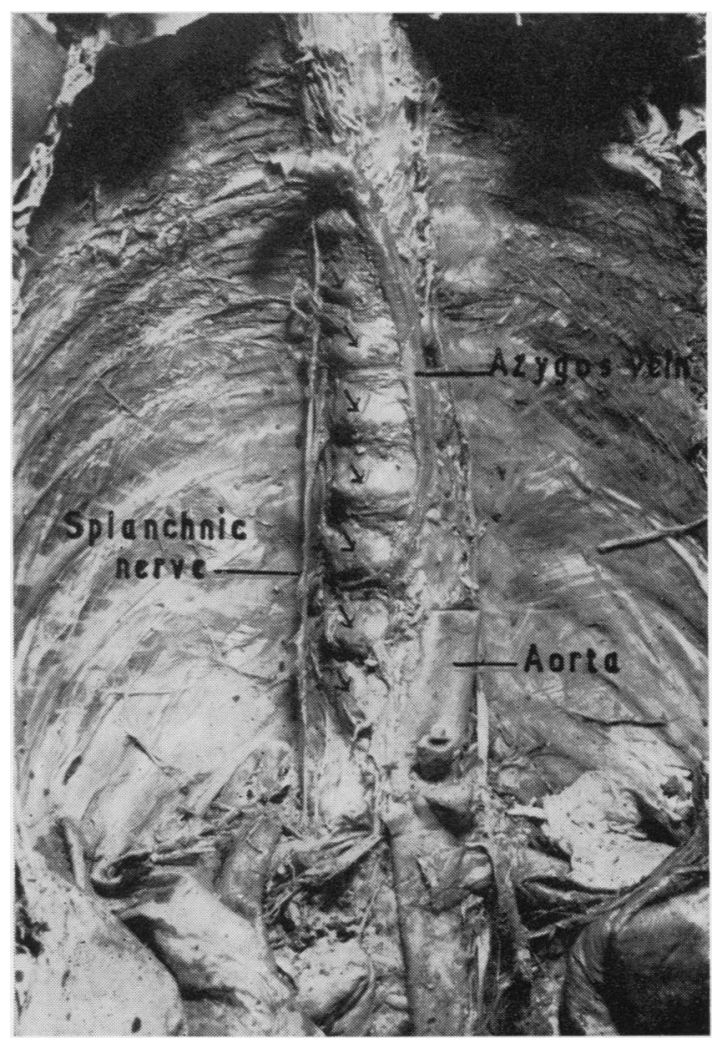

Fig. 1.-Azygos vein crossing to the left side. The aorta has been removed. The azygos vein is clearly seea running its longitudinal arched course on the left side of the vertebral column. Osteophytes (arrows) are seen bulging on the right side. 
vertebral column, it returned to the right side, thus crossing the midline again to reach its normal termination in the vena cava. In this latter part of its course the vein first runs obliquely upwards and to the right to pass anterior to the vertebral column and posterior to the right bronchus. Here it turns forwards over the right bronchus and terminates in the superior vena cava. The azygos vein thus described performs a wide longitudinal arch convex to the left and twice crosses the midline. The first (inferior) crossing is most frequently found at the level of the eleventh thoracic vertebra, varying from the eighth to the twelfth. The superior crossing was generally observed at the level of the sixth or seventh thoracic vertebra varying between the fifth and the eighth.

In 35 cases $(27 \%)$ of the adult bodies and in three $(15 \%)$ of the stillborn infants, the azygos vein described a very similar arch, but the maximum of convexity of the arch reached only as far as the midline of the vertebral column: here the vein ran for a variable distance without passing to the left side. In the remaining $26(20 \%)$ adults and 14 foetuses $(70 \%)$ the azygos vein remained on the right side of the vertebral column, conforming with the classical description.

\section{TABLE I}

FREOUENCY AND PERCENTAGE OF DIFFERENT COURSES OF AZYGOS VEIN IN RELATION TO MIDLINE IN 150 CASES

\begin{tabular}{l|c|c|c|c}
\hline & $\begin{array}{c}\text { Only on } \\
\text { Right }\end{array}$ & $\begin{array}{r}\text { Reaching } \\
\text { Midline }\end{array}$ & $\begin{array}{r}\text { Crossing } \\
\text { to Left }\end{array}$ & Total \\
\hline $\begin{array}{l}\text { A. Adults } \ldots \text { Stillborn infants .. } \\
\text {.. }\end{array}$ & $\begin{array}{r}26(20 \%) \\
14(70 \%)\end{array}$ & $\begin{array}{r}35(27 \%) \\
3(15 \%)\end{array}$ & $\begin{array}{r}69(53 \%) \\
3(15 \%)\end{array}$ & $\begin{array}{r}130 \\
20\end{array}$ \\
\hline
\end{tabular}

In the majority of the adult cadavers osteophytes on the vertebrae were present; these were noted to be well developed, chiefly on the right side of the thoracic vertebrae, i.e., in the concavity of the longitudinal arch of the azygos vein (Figs. 1 and 2). The aorta was generally found following a course parallel to that of the azygos vein; it was also displaced to the left in those cases where the azygos vein passed to that side. In this way their normal mutual relationship was maintained (Fig. 2).

\section{Conclusions AND Discussion}

From the foregoing description it can be seen that in the great majority of the stillborn infants the azygos vein kept to its course on the right side, whereas its most frequent course in old adults was to cross to the left or to pass upwards to the left as far as the midline. Although the number of infants dissected was small, the findings suggest that during life the vein changes course. As no bodies of older children and young adults were dissected, it was notô? possible in this work to establish the age at whicho the deviation most frequently begins.

Although no definite conclusions regarding the $\frac{\overline{\bar{c}}}{\overline{2}}$ cause of the displacement of the azygos vein can be $\frac{\mathbb{\Phi}}{\alpha}$ drawn from these dissections, the accompanyingo displacement of the aorta and the presence of ${ }^{\text {s }}$ osteophytes seem to offer alternative explanations. $\stackrel{\circ}{\circ}$

The frequently seen elongation and displacement $\vec{\omega}$ of the aorta to the left is part of the ageing process, $\stackrel{\omega}{\stackrel{D}{ }}$ and is generally attributed to arteriosclerotic changes. The preservation of the parallelism between the ${ }_{\vec{T}}^{x}$ azygos vein and the displaced aorta, the vein some- $c$ times even following all the sinuosities of the artery $\omega$ (Fig. 2), would suggest that the latter causes the 응

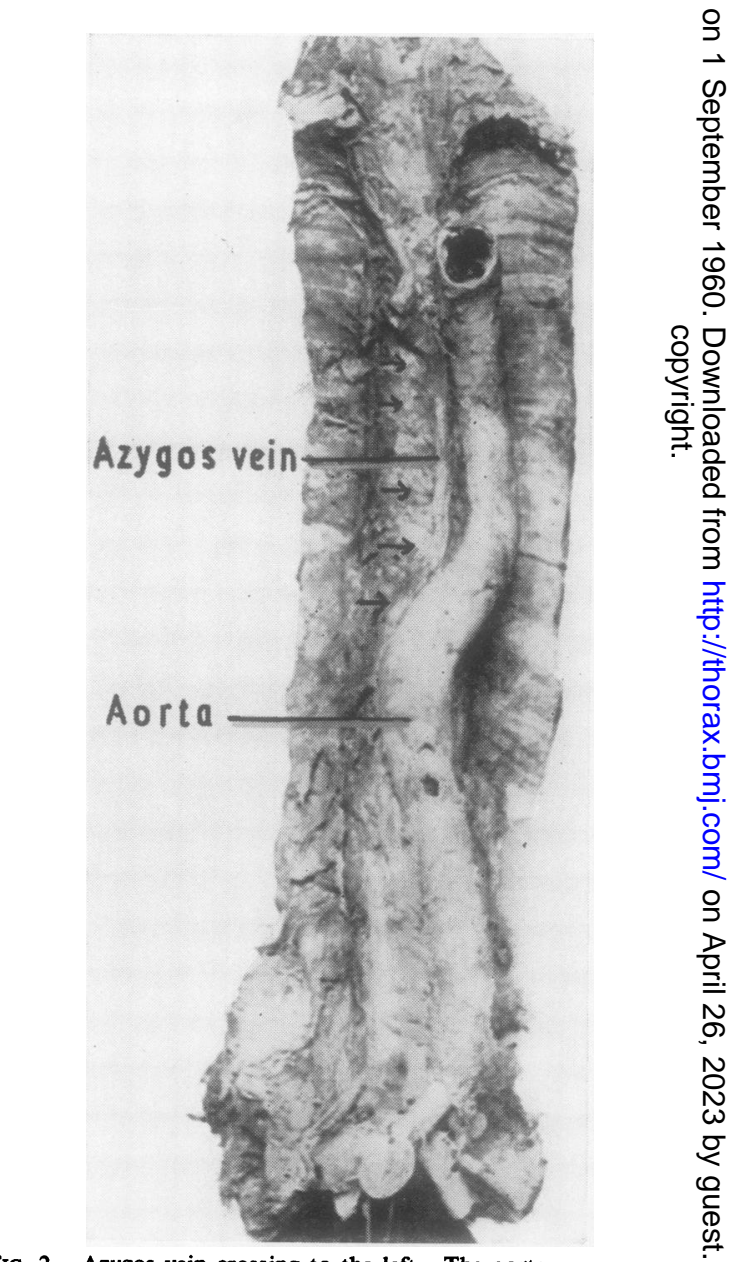

FIG. 2.-Azygos vein crossing to the left. The aorta appears very tortuous and is displaced to the left; the azygos vein follows the curves of the aorta very closely; osteophytes (arrows) bulge on the right side of the thoracic vertebral column. 


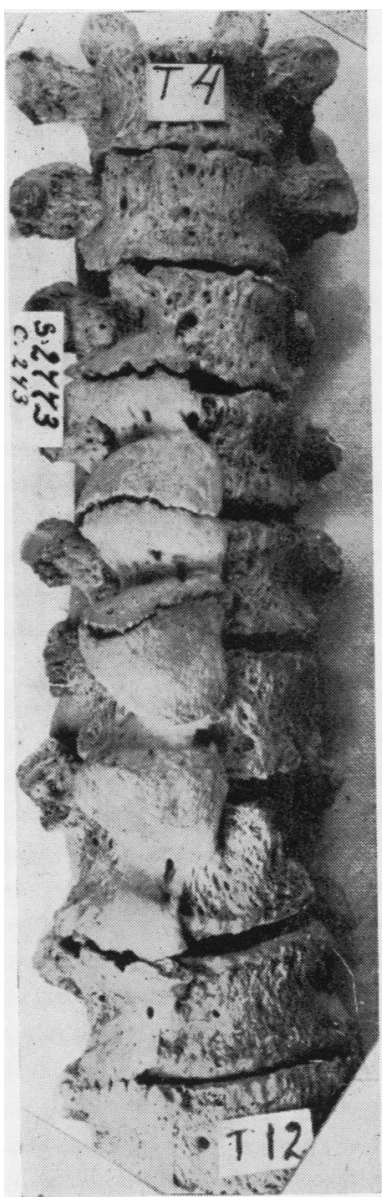

FIG. $3 a$

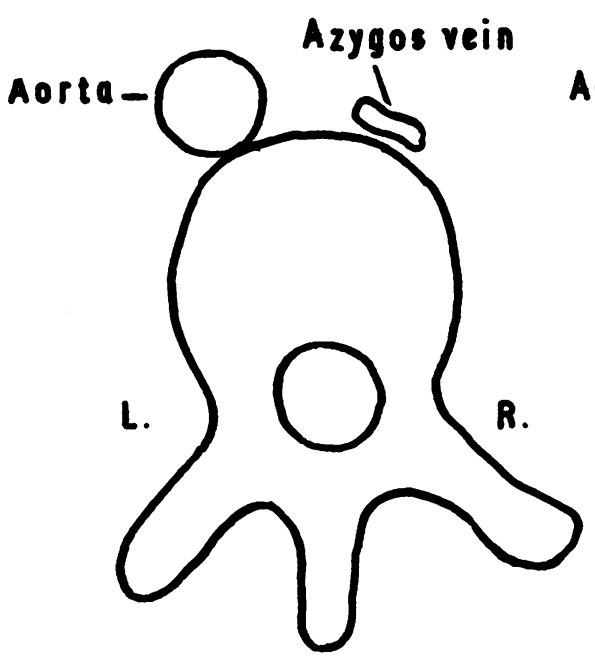

FIG. $4 a$
Fig. 3.-Typical pattern of development of osteophytes in the thoracic spine of (a) a 65-year-old and (b) a 88-year-old person. (a) Osteophytes have developed predominantly on the right side from the sixth to the twelfth thoracic vertebrae. (b) The ninth thoracic vertebra showing extreme development of an osteophyte as seen from above; the osteophyte projects forwards and to the right, producing a characteristic asymmetry of the vertebral body.

FIG. 4.-Diagrams of (a) relations of aorta and azygos vein to normal vertebral column; (b) displacement of azygos vein to the left $(L)$, with development of osteophyte on right side (R) of the vertebrae.

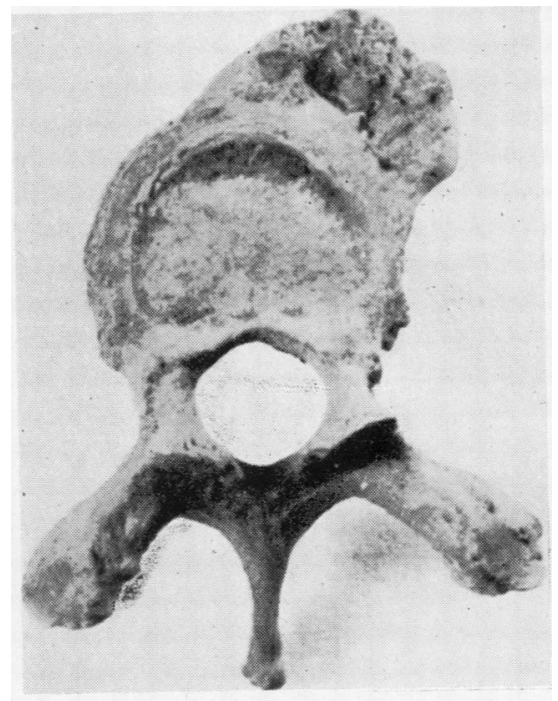

Fig. $3 b$

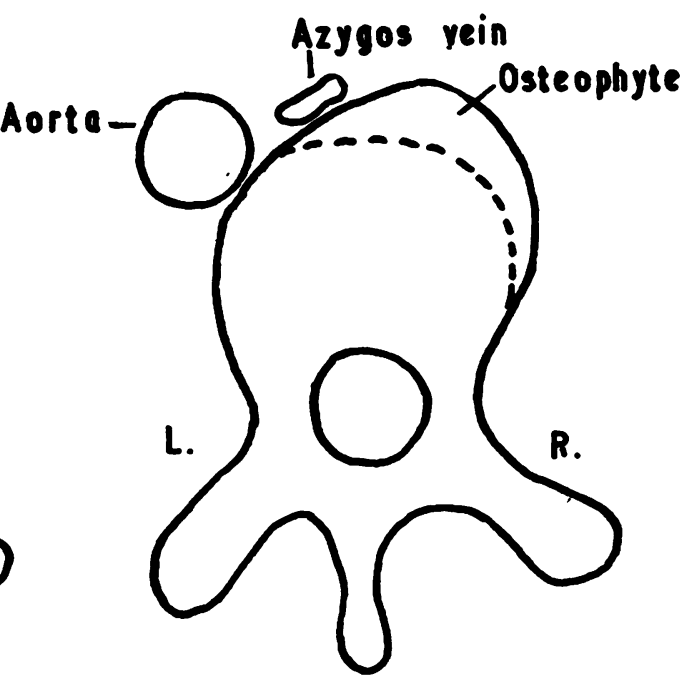

FIo. $4 b$ 
deviation of the azygos by pulling on the connective tissue and the multiple vascular elements (right intercostal arteries and hemiazygos veins) which lie between them. This seemed to be confirmed during dissection; if the aorta is drawn to the left the azygos vein is seen to follow it.

On the other hand, the development of osteophytes in the thoracic region, predominantly on the right side of the vertebrae (Figs. 3 and 4), may also be related to the deviation of the azygos vein to the left.

Osteophytosis, a generalized phenomenon along the vertebral column with advancing years, is considered to be caused by the mechanical stresses and strains acting on the vertebral column. The asymmetric growth of the osteophytes in the thoracic region is apparently due to an inhibitory influence on their development which is exerted by the aorta running along the left side of the vertebral column. In the lower thoracic and lumbar regions where the aorta runs in the midline, osteophytes are seen to develop symmetrically on both sides (Nathan, 1960). Thus the asymmetrical development of the vertebral bodies seems to cause the deviation of the azygos vein by pushing it to the left (Fig. 4).

Which of these mechanisms is actually responsible for the displacement of the vein, or whether both participate in its displacement, is difficult to establish from the present work. Other unknown factors cannot be excluded.

A knowledge of the displacement of the vein might be of importance with the development of new techniques and the increasing use of azygography as a diagnostic procedure (Fischgold et al., 1952; Süsse and Aurig, 1954; Tori, 1954; Lucarelli et al., 1955; Abrams, 1957; Schwartz et al., 1959).

Tori (1954), in radiological studies and some dissections, observed that the azygos vein is generally found more medially in front of the vertebral column than is usually described. More recently, Schwartz et al. (1959), coming to very similar conclusions in their azygographic study, state that “. . . the thoracic portion of the azygos often appears to be much further to the left than has been indicated."

The fact that a displacement of the vein is considered to be a radiological sign of pathological processes in the thorax, such as mediastinal tumours, left atrial enlargement, and pulmonary atelectasis, obliges one to bear in mind the frequency with which the azygos vein may be found "displaced" in the absence of any of these pathological conditions.

\section{SUMMARY}

The variations in the course of the azygos vein in relation to the midline are described in a group of 150 dissected bodies, 130 of which were of old persons and 20 of stillborn infants. In the bodies of the elderly adults the azygos vein was found frequently to cross the midline to the left $(53 \%$ of cases) and then to return to the right, to terminate as usually described. In $27 \%$ of cases it passed to the left only as far as the midline. In the stillborn infants, the azygos vein ran its course most frequently $(70 \%)$ on the right as classically described. The possible causes of the displacement of the azygos vein to the left are discussed with special reference to the elongation of the aorta and the predominant development of osteophytes on the right side of that part of the thoracic vertebral column. Its importance in the correct interpretation of azygographs is stressed.

I wish to express my thanks to Professor R. G. Williams, of the Department of Anatomy of the Pennsylvania University Medical School, and to Professor J. L. Angel, of the Daniel Baugh Institute of Anatomy of the Jefferson Medical School, and to the staff of their departments for making it possible for me to utilize theo material from their respective laboratories. I am also indebted to Professor M. Ickowitz and to Dr. G. Gitlite for their revision and constructive criticism of this manuscript and to Mrs. E. Salomon for the illustrations and photographs.

\section{REFERENCES}

Abrams, H. L. (1957). 'Radiology, 69, 508.

Borsetto, P. L. (1956). Excerpta Med. Section 1; Vol. X; abst. no. 12, p. 5 .

Burke, D. T., and Goldberg, L. (1949). Canad. met. Ass. J., 60, 271 .

Butler, H., and Balankura, K. (1952). Anat. Rec., 113, 409.

Dal Zotto, E., and Borsetto, P. L. (1954). Atti Soc.med.-chir., Padova, 1953, 31, 473 .

Ellis, F. H., and Bruwer, A. (1954). Proc. Mayo Clin., 29, 508.

Fischgold, H., Adam, H., Écoiffier, J., and Piéquet, J. (1952). J. Radiol. Electrol., 33, 37.

Fleischner, F. G., and Udis, S. W. (1952). Amer. J. Roentgenol., 67, 569.

Howden, R. (1886). J. Anat. (Lond.), 21 (n.s. 1), 72

Huffmire, A. P., and Bower, G. C. (1919). Anat. Rec., 17, 127.

Keyes, D. C., and Keyes, H. C. (1925). Ibid., 31, 23.

Lucarelli, U., Carnevali, G., and Vincre, G. (1955). Atti Soc. lombarda Sci. med. biol., 10, 142 .

McCotter, R. E. (1916). Anat. Rec., 10, 371.

Morison, B. G. (1879). J. Anat. (Lond.), 13, 346.

Nathan, H. (1960). Report in preparation.

Nguyen-Huu (1957). C.R. Ass. Anat., Bull., No. 96, p. 619.

Ottonello, P. (1931). Lotta c. Tuberc., 2, 1323.

Schwartz, S., Handel, J., and Candel, S. (1959). Radiology, 72,

338 .
Shuford, W. H., and Weens, H. S. (1958). Amer. J. Roentgenol., 80,

S25. W. C. (1916). Anat. Rec., 11, 191.

Stauffer, H. M., LaBree, J., and Ádams, F. H. (1951). Amer. J. Roentgenol., 66, 353.

Süsse, H. J., and Aurig, G. (1954). Fortschr. Röntgenstr, 81, 335.

Tori, G. (1954). Brit. J. Radiol., 27, 16. . (1958). Acta anat. (Basel), 32, 235 . 